University of Nebraska - Lincoln

DigitalCommons@University of Nebraska - Lincoln

Faculty Publications from the Harold W. Manter Laboratory of Parasitology

4-1950

\title{
Observations on Histopathological Changes Associated with Starvation in Wisconsin Deer
}

Robert L. Rausch

Arctic Health Research Center, rausch@u.washington.edu

Follow this and additional works at: https://digitalcommons.unl.edu/parasitologyfacpubs

Part of the Parasitology Commons

Rausch, Robert L., "Observations on Histopathological Changes Associated with Starvation in Wisconsin Deer" (1950). Faculty Publications from the Harold W. Manter Laboratory of Parasitology. 563.

https://digitalcommons.unl.edu/parasitologyfacpubs/563

This Article is brought to you for free and open access by the Parasitology, Harold W. Manter Laboratory of at DigitalCommons@University of Nebraska - Lincoln. It has been accepted for inclusion in Faculty Publications from the Harold W. Manter Laboratory of Parasitology by an authorized administrator of DigitalCommons@University of Nebraska - Lincoln. 


\title{
OBSERVATIONS ON HISTOPATHOLOGICAL CHANGES ASSOCIATED WITH STARVATION IN WISCONSIN DEER
}

\author{
Robert Rausch ${ }^{1}$ \\ Department of Wildlife Management, University of Wisconsin, Madison
}

Heavy winter losses in deer, apparently resulting directly from an inadequate food supply, have long been known in the United States. The general situation has been well reviewed by Leopold (1943) and by Leopold, Sowls, and Spencer (1947). There is a considerable volume of literature available concerning deer starvation from the management standpoint. The ill-advised attempts at the total destruction or, at best, the severe reduction of natural predators on deer have resulted in the removal of this important population control. In addition to this, in most regions there is so much public antagonism to artificial control of deer populations that it is rarely effected, even

1 Now with the U. S. Public Health Service, Box 960, Anchorage, Alaska. though it be recognized by qualified men that remedial measures are necessary.

The observations recorded in this paper were made during a study of helminth parasitism in Wisconsin deer. This permitted a brief exploration of verminous bronchial pneumonia which, according to some writers, is often an important accompanying condition associated with malnutrition. With this in mind, I autopsied about 20 Wisconsin deer dead from starvation without finding any evidence of pneumonia, even though heavy lung-worm infections (Protostrongylus) were present. The post-mortem alterations in these carcasses did not allow completely satisfactory results. Through the generous cooperation of the Wisconsin Conserva- 
tion Department, it was later made possible for me to collect deer from an area where starvation was much in evidence.

Five starving deer were collected by shooting on March 9 and 10, 1948, at the time of the year when the deer were suffering most heavily from food shortage. An effort was made to select animals obviously suffering from the effects of inadequate diet. We were successful in this, although it is well known that deer usually show little visible effect of starvation until they are near death. In this study, I was aided in the collection of these deer by Messrs. Bruce Stollberg and Harry Stroebe, of the Game Division of the Wisconsin Conservation Department, and by Mr. Werner Radke, of the Department's Enforcement Division. This opportunity is taken to express my appreciation of their aid.

I realize that 5 animals hardly represent an adequate sample. It is difficult, however, to justify the destruction of a very large number of deer for research purposes only, in view of the usual public reaction to such activities. Two normal deer, for comparative purposes, were obtained later during the early fall.

The 5 starved deer studied were collected in the central part of Wisconsin, in Jackson County, while the normal animals came from the northern part of the State. At the time the deer were obtained there were about 6 inches of snow, and subzero temperatures. Although the area from which the deer were taken is far enough south so that the animals do not yard, there was much evidence of overbrowsing, and an intensive program of artificial feeding was being carried out. We found a considerable number of fawns dead in the feeding areas, where alfalfa hay and concentrate were available. Stollberg (1949) has given additional information on this situation.

The deer were autopsied immediately after being shot, and the desired tissues were fixed at once in 10 per cent formalin and in formalin-acetic acid-alcohol solution. Blood smears were unfortunately ruined by the subzero temperatures, since they froze immediately when made. The tissues fixed in formalin-acetic acid-alcohol were imbedded in paraffin, sectioned, and stained with Weigert's haematoxylin with a modification of Crossman's modification of Mallory's triple stain. Tissues fixed in 10 per cent formalin were frozen-sectioned and stained with Sudan IV for fat. The latter method was applied routinely to bone marrow, kidney, liver, and heart tissue. Bensley's mitochondria stain was applied to the bone marrow. The prussic acid test was applied to splenic tissue as a test for iron pigments and, in some cases, other special techniques were used.

\section{Results}

The histological findings for the five starved deer were in general the same; however, each animal is considered separately in order to allow a more complete report.

Deer I: A female fawn weighing 51 pounds; very thin, but not noticeably weak. Some indication of the age of this animal can be gained from the fact that one permanent molar and one permanent incisor were present. Gross findings of a pathological nature were few. However, the heart was noted to be very 
flabby and yellowish in color, and the bone marrow was gelatinous. The animal was killed in an area where some downed pines furnished temporary food. However, dead fawns of a similar size (from 50 to 55 pounds) were picked up in the immediate area.

Microscopical findings: A marked decrease in the fat content of the bone marrow of both the shaft and head of the long bones was obvious. Few hemopoietic cells were seen (Plate 6A). The spleen showed thickening of arterial walls (Plate $6 \mathrm{~B}$ ), and a decrease in size and number of follicles. Considerable hemosiderin was seen throughout the spleen; this was identified by Turnbull's method. An unidentified pigment which remained unstained by the above reaction was also present in considerable quantities. Fatty degeneration had taken place in the heart. The liver showed abundant hemosiderin in the Kupfer cells, as demonstrated by the Turnbull method. A finely-granular pigment was observed in the cytoplasm of the liver cells in the areas surrounding the central veins. This pigment stained red by Turnbull's reaction. According to Lillie (1947) this pigment would be hemofuchsin. The kidneys showed chronic passive congestion and a thickening of arterial walls. A granular material, which stained red with acid fuchsin, was abundant in Bowman's space and within the proximal convoluted tubules. A proliferation of the cells of Bowman's capsule was noted. The lungs were normal except for numerous granulomatous lesions resulting from lung-worm infections (Plate 6C). In this animal, an average of 10 granulomata were seen per low-power field. Eosinophiles were numerous in the subepithelial connec- tive tissue of the small intestine.

Deer II: An adult female, at least 3 years old; very thin, weighing only 90 pounds. Except for the gelatinous bone marrow, there were no striking gross lesions. The heart was not obviously affected.

Microscopical findings: There was a marked decrease in the amount of fat in the marrow of the long bones. Hemopoietic cells were rare. A thickening of the arterial walls was seen in the spleen, along with a decrease in the size and number of follicles. Hemosiderin was abundant in the spleen, as was the unidentified pigment observed in the spleen of deer I. Some fatty degeneration of the heart was noted. Hemosiderin was abundant in the Kupffer cells of the liver. The kidneys showed chronic passive congestion and a thickening of the arterial walls. A granular material was abundant in Bowman's space and in the proximal convoluted tubules (Plate 6D). A proliferation of the cells of Bowman's capsule was also noted. The lungs were normal except for numerous lung-worm granulomata. Eosinophiles were numerous in the subepithelial connective tissue of the small intestine. The mesenteric lymph nodes showed a thickening of the arterial walls, moderate fibrosis, and a marked decrease in the size and number of follicles.

Deer III: A small adult female, weighing 104 pounds, in relatively good condition. Some subcutaneous fat was present, along with considerable fat on the mesentery. Fat was also rather abundant in the bone marrow, which appeared nearly normal in contrast to the gelatinous marrow seen in the other animals. A single fawn was found in the uterus of this animal. A cysticercus of 
Taenia sp. was observed on the surface of the liver.

Microscopical findings: The bone marrow was nearly normal in fat content, although there was some decrease in amount. Hemosiderin was abundant in the spleen, and there was a decrease in the number and size of the splenic follicles. The endothelial lining of the arterioles, along with the subepithelial connective tissue, extended into the lumen; in many of the arterioles the lumina were nearly occluded. The arterial walls were thickened. The heart showed chronic passive congestion. Hemosiderin was abundant in the liver, and there was a marked fibrosis of interlobular tissue. The epithelium of the bile ducts showed considerable proliferation. The kidneys showed a tendency toward a high cellularity of the glomerular tufts, with a small amount of granular material within the Bowman's space and in the tubules. The lungs were normal except for a moderate number of lung-worm granulomata (2 or 3 per low-power field). The intestine showed a moderate infiltration by eosinophiles and lymphocytes.

Deer IV: A 51-pound male animal, in poor condition. Two permanent molars, the second just coming through, and two permanent incisors were present. This animal was found lying among the alfalfa piles in a feeding area. It ran rather well when disturbed, but was easily overtaken and shot. The heart of this animal appeared good on gross examination, with little evidence of fatty degeneration. The bone marrow was gelatinous.

Microscopical findings: The bone marrow showed practically no fat. The spleen showed an abundance of hemo- siderin, and proliferation of arterial walls with the attendant projection of the lining into the lumina. The follicles had decreased in size and number. No changes were seen in the heart. The nuclei of the hepatic cells showed vacuolation. Interlobular fibrosis was noted, accompanied by some atrophy. Hemosiderin was abundant in the Kupffer cells. A marked fibrosis of the arterial walls was seen in the kidneys. A small amount of granular material was seen in the proximal convoluted tubules and in the glomerular space. The lungs were normal except for lung-worm granulomata (about 1 per low-power field). There was a moderate infiltration of eosinophiles in the small intestine.

Deer $V:$ An emaciated female animal, weighing 54 pounds. Three permanent molars were present, with the third one just coming through. The animal was obviously weak. The heart was flabby and yellowish in color, and the bone marrow was gelatinous.

Microscopical findings: There was little fat in the bone marrow, and hemopoietic cells were not observed. The spleen showed thickening of the arterial vessel walls, with the mucosa projecting into the lumina. The heart was markedly congested and showed fatty degeneration. Although the animal was young, there was considerable pigment around the nuclei of the cardiac muscle cells. There was some hemosiderin in the Kupffer cells of the liver. There was a thickening of the arteriole walls of the kidney. A red-staining granular material was apparent in Bowman's capsule, and in the proximal convoluted tubules. The lungs were normal. Eosinophiles were present, but not numerous, in the small intestine. 


\section{Discussion}

Numerous retrogressive changes appeared in the deer suffering from starvation. These findings indicate that even the animals which seem to be in good condition (as deer III) may have suffered considerable damage. The importance of such damage to the animal which survives the periods of malnutrition is not understood; it may be, however, that such damage might contribute to a gradual deterioration of the herd in general.

Little information is available on the normal histology of the white-tailed deer. We have made comparisons with the tissues of two normal deer obtained during the early autumn of 1948 . These animals, an adult doe and a fawn, were collected before any browse shortage developed. With the exception of lungworm granulomata, these animals showed none of the changes recorded above.

Although the presence of considerable hemosiderin in the spleen of adult deer is a normal condition, it probably represents evidence of excessive blood destruction in fawns. It is generally accepted that pigment around the nuclei of the cardiac muscle cells in some mammals (e.g., man ) occurs only in old age. This condition in a young animal (deer V) probably should be considered pathological. The situation in the spleen in regard to the apparent thickening of the arterial walls is not clear. It is possible that with the diminished splenic activity the organ contracts, allowing the arterioles to contract and give the appearance that their walls are much thickened. I am of the opinion, however, that the muscular coat of these arteries and arterioles was hyper- trophied. Mitochondria of the granular type were abundant in the cytoplasm of the fat-cells in the bone marrow of the starved deer. These fat-cells contained no fat droplets, as mentioned above. Such mitochondria were also observed in the bone marrow of the normal deer in cells which contained no fat. Although a few mitotic figures may be seen in the epithelium of the intestine of normal animals, they were particularly numerous in two of the starved deer.

Certain conditions observed in the starved deer appear to be particularly evident. They were: abundant hemosiderin in the spleen of the fawns; marked decrease in the amount of fat in the bone marrow; rarity of hemopoietic cells in the bone marrow, and reduction in number and size of follicles in the spleen; a deposition of acidophilic granular material in Bowman's space and in the proximal convoluted tubules of the kidneys, along with cellular hypertrophy of Bowman's capsule; fatty degeneration of the heart.

The only commonly observed helminth, in addition to lung-worms, was Ostertagia odocoilei Dikmans, 1931. Light infections of this nematode were seen in most of the deer examined. A cysticercus of Taenia sp. was found on the surface of the liver of one animal. Some of the animals were found to be heavily infested with a louse, Cervicola virginianus (Peters) 1930; in some cases these were found in large numbers on starved deer which had been dead for some time.

As mentioned earlier in this paper, I have seen no evidence of pneumonia, verminous or otherwise, in any of the deer I examined. Nearly all the deer 
Rausch in Journal of Wildlife Management (April 1950) v. 14, no. 2, p. 156-161, plates 6-7.

Copyright 1950, Wildlife Society. Used by permission.

Journal of Wildlife Management, Vol. 14, No. 2 Plate 6
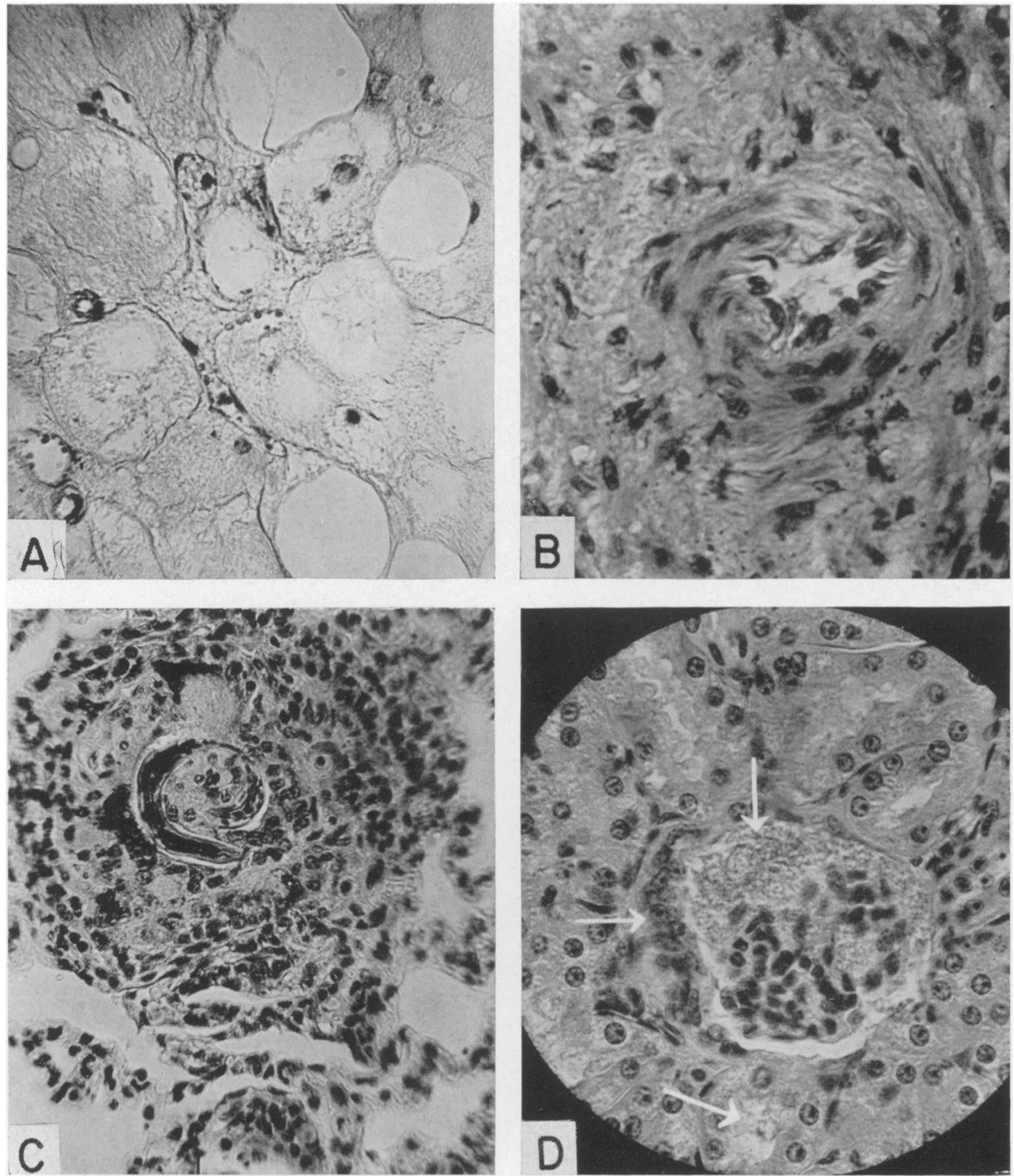

Explanation of Plate 6.

A. Bone marrow, stained with haematoxylin and Crossman's triple stain, showing lack of hemopoietic cells in the epiphyseal region. High: power.

B. Apparent thickening of wall of arteriole in the spleen. High power.

C. Typical lung-worm granuloma in the lung. High power.

D. Glomerulus of kidney showing proliferation of Bowman's capsule and granular material in Bowman's space and in proximal convoluted tubule. High power. 
Rausch in Journal of Wildlife Management (April 1950) v. 14, no. 2, p. 156-161, plates 6-7.

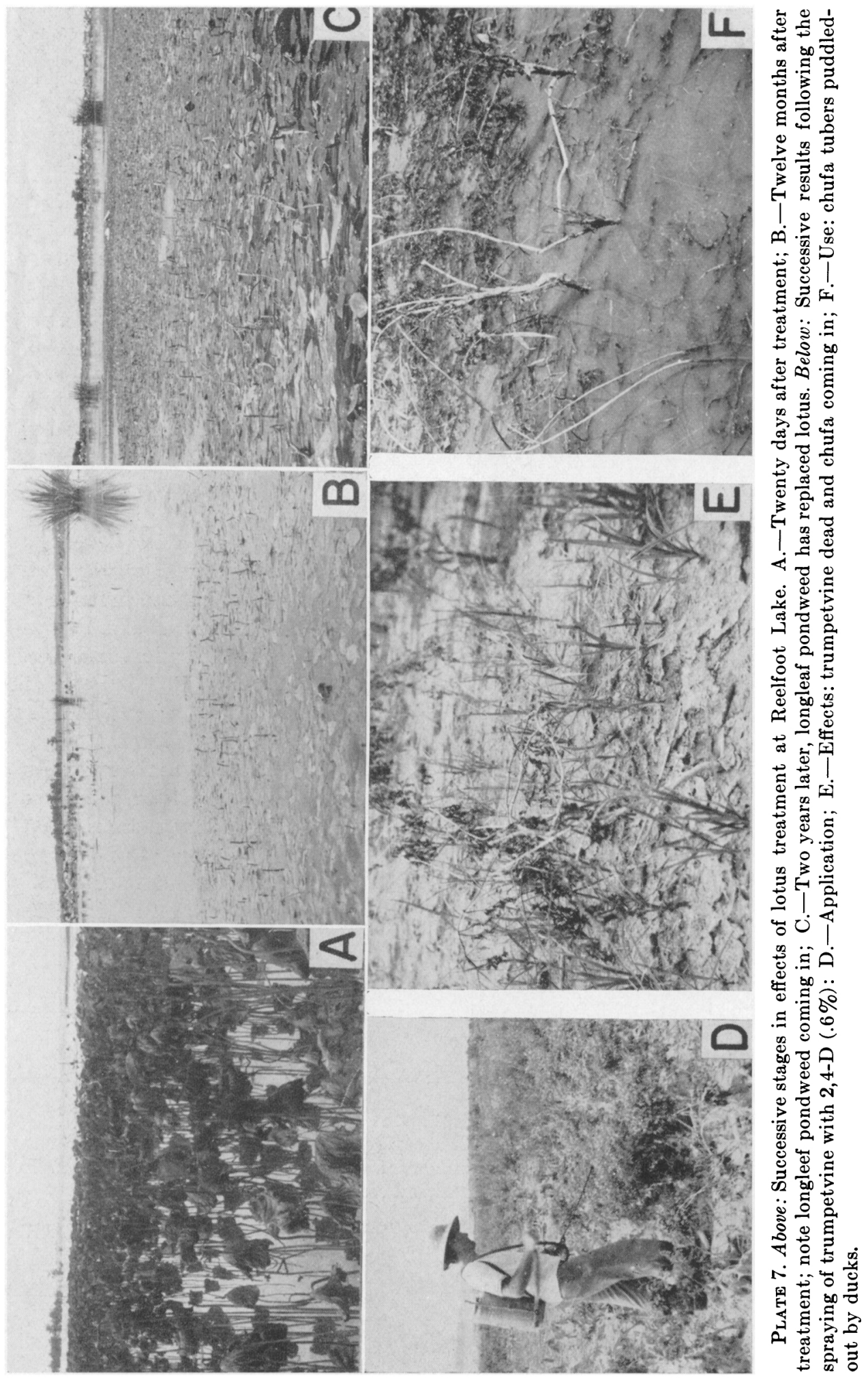


examined, including those found dead, were infected with Protostrongylus sp. The requisite conditions as outlined by O'Roke (1948) existed ("abnormally high population of deer, the adult deer generally infested, environmental and intermediate host conditions such that fawns have early opportunities to become heavily infested, ... a shortage of food and resultant malnutrition, weather conditions such as an exceptionally severe or an exceptionally late winter storm ...")-supposedly predisposing the animals to verminous pneumonia. It should be pointed out also that the majority of the animals dead from starvation were fawns-i.e., animals born the previous spring. No evidence of pneumonia could be demonstrated in any of the animals dead from starvation. Neither did I observe the "interstitial pneumonia" reported by Goble (1941). It is possible that the animals studied by him had been affected by conditions brought about by their confinement in the George Reserve. Possibly they became more heavily infected with lung-worms than do the animals living under natural conditions in Wisconsin.
In conclusion, I am of the opinion that winter deer losses in Wisconsin are caused directly by starvation uncomplicated by verminous pneumonia. Post-mortem hemostasis in the lungs of deer dead from starvation may be frequently interpreted as evidence of pneumonia by non-technical personnel.

\section{Literature Cited}

Goble, F. C. 1941. Tissue changes in white-tailed deer (Odocoileus virginianus borealis) accompanying natural infections of lungworms (genera Protostrongylus and Dictyocaulus). Journ. Wildl. Man., 5: 141-158.

LEOPOLD, A. 1943. Deer irruptions, in Wisconsin's deer problem. Wis. Cons. Dept. Pub. 231, pp. 1-11.

-., L. K. Sowls, and D. L. Spencer. 1947. A survey of over-populated deer ranges in the United States. Journ. Wildl. Man., 11: 162-177.

Lillie, R. D. 1947. Histopathologic technic. Blakiston Co., Philadelphia and Toronto. $300 \mathrm{pp}$.

O'Roke, E. C. 1948. Diseases and parasites of wild animals. in R. E. Trippensee: Wildlife management, McGraw-Hill, New York, pp. 369-384.

StollberG, B. P. 1949. Deer starve at feeding stations. Wis. Cons. Bull., 14: 18-19. 